\title{
ESTRATÉGIAS COGNITIVAS DE COMPREENSÃO DO HUMOR DE UMA TIRA CÔMICA
}

Rafahel Jean Parintins Lima ${ }^{1}$

\section{RESUMO}

O objetivo deste texto é elencar as estratégias cognitivas exigidas para a compreensão dos sentidos envolvidos no humor de um espécime textual do gênero tira cômica. Realizamos, primeiramente, uma apresentação dos estudos da construção textual do humor em tiras cômicas. Posteriormente, tratamos do fenômeno da compreensão de textos na perspectiva sociocognitiva da linguagem (VAN DIJK, 2012; KOCH, 2011b), explicitando a pergunta que guia este trabalho. Em seguida, apresentamos e analisamos uma tira cômica da série Níquel Náusea, de Fernando Gonsales, cartunista brasileiro. Nossas análises se centram na materialidade textual no sentido de apontar os processos cognitivos exigidos para a compreensão textual. Os resultados obtidos sublinham a exigência da interpretação de elementos verbais e não-verbais, da identificação do caráter de comicidade dos elementos semiológicos, do reconhecimento do gênero tira cômica, da evocação de situações por meio dos elementos verbais e não-verbais e da identificação de (in)verossimilhança. Concluímos que essas exigências cognitivas se diferenciam, no entanto, em seu grau de importância para a compreensão do humor na tira, sendo a evocação de cenas por meio dos elementos semiológicos a mais determinante.

Palavras-chave: Sentido. Compreensão. Humor. Quadrinhos. 


\title{
COGNITIVE STRATEGIES FOR THE HUMOUR COMPREHENSION OF A CARTOON
}

\begin{abstract}
We aim at enumerating cognitive strategies required to the comprehension of meanings involved in humor, specifically in little comics. We briefly summarize studies in the construction of humoristic comics. Afterwards, we present studies about sociocognitive approach (VAN DIJK, 2012; $\mathrm{KOCH}, 2011$ ) of text comprehension), presenting our problem. We present and analyze a text from Níquel Náusea comics series, by Fernando Gonsales. Our results underline the need of interpreting verbal and non-verbal elements, identifying the comicalness character of semiologic elements, recognizing the humoristic comics genre, evocating situations from verbal and non-verbal elements and, finally, identifying plausibility. We conclude that these cognitive operations have different grades of importance for the humor comprehension of humoristic comics, remarkably the evocation of scenes through semiologic elements.
\end{abstract}

Key-words: Meaning. Comprehension. Humor. Comics.

\section{INTRODUÇÃO}

Este artigo tem o objetivo de desvendar as estratégias cognitivas necessárias para a compreensão de sentidos envolvidos no humor, especificamente em uma tira cômica da série Níquel Náusea, de Fernando Gonsales. Primeiramente, apresentamos, de forma resumida, estudos sobre construção do humor em tiras cômicas. Posteriormente, tratamos da compreensão de texto na abordagem sociocognitiva (VAN DIJK, 2012; KOCH, 2011b), apresentando o problema investigativo em questão. Em seguida, apresentamos e analisamos o espécime textual apontado acima. Nossos resultados sublinham a exigência principal das seguintes operações cognitivas: interpretar os elementos verbais e não-verbais, identificar o caráter cômico de certos elementos semiológicos, reconhecer o gênero tira cômica, evocar situações por meio de elementos verbais e não-verbais e, por 
fim, julgar a plausibilidade das cenas evocadas. Concluímos que essas operações cognitivas têm diferentes graus de importância para a compreensão do humor na tira cômica em questão, sendo a evocação de cenas através de elementos semiológicos a estratégia mais decisiva.

\section{ASPECTOS TEXTUAIS E COGNITIVOS DAS TIRAS CÔMICAS}

Segundo Santos (2002), a tira cômica contém uma piada, isto é, uma narrativa de humor, que constitui sua essência, mas também contém elementos visuais (que muitas vezes correspondem funcionalmente às sequências narrativas do gênero piada). O humor tanto do gênero piada quanto do gênero tira cômica são da mesma natureza. Para Cagnin (1975), o humor é gerado em um processo sequencial em que se mostram uma situação inicial, um elemento modificador dessa situação e, finalmente, a disjunção, que é o dispositivo provocador do humor. Para Cagnin, no caso das tiras, tanto a semiose da imagem quanto a da língua podem ser disjuntoras.

Para Gil (1991; 1998), por sua vez, o humor resulta da passagem de um cenário verossímil a outro inverossímil. Da mesma forma, para Raskin (1985), o humor é gerado pela mudança de um script bona fide, isto é, um sentido verossímil, para um script não-bona fide. Notemos que esses dispositivos não são específicos à geração do humor, já que também podem estar em jogo na construção de narrativas em geral. Essas teorizações, resumidas por Ramos (2007), pouco evocam diretamente o tipo de trabalho cognitivo necessário para a compreensão do humor, mas podemos perceber, no mínimo, que a compreensão do humor vai depender de dispositivos que permitam a compreensão do que seja, no caso, "verossímil" ou não, e do reconhecimento dos efeitos da disjunção cômica a que Cagnin se refere. $O$ efeito de humor (que pode ser respondido com uma variedade de respostas corporais, mentais e emocionais) é resultado de um processamento cognitivo em cumplicidade com o material textual.

É evidente que o humor, em uma acepção mais geral, não existe apenas em piadas, e muito menos o chamado "senso de humor". O humor pode estar em muitos processos, de forma mais sutil. No caso da tira que analisamos, a própria forma caricatural com que as personagens são desenhadas lhes impregna de um caráter cômico: assim como a vestimenta de um palhaço qualquer por si só já carrega 
comicidade. Mas quando falamos de humor neste trabalho, falamos do humor elaborado textualmente (através de dispositivos específicos) e cognitivamente (através de determinadas estratégias).

Para compreender diálogos, por exemplo, que fazem parte do gênero tira em quadrinho, é necessário acionar o arsenal de esquemas textuais (BENTES, 2007) relacionados a esses diálogos e conhecimentos sobre as implicaturas conversacionais, conhecimento de mundo, conhecimento da língua, etc., ali envolvidos (cf. VAN DIJK, 1992).

\section{A COMPREENSÃO DE TEXTOS}

O que está em jogo na compreensão de textos é, no fim das contas, a compreensão das pessoas entre si. Estar cognitivamente imerso no ambiente que nos envolve e perceber outras pessoas como "não-eus", como co-específicos (TOMASELLO, 2003) fazem parte dessa compreensão. Essas capacidades cognitivas, junto com o enquadramento de certos elementos do entorno como sendo elementos semiológicos (SALOMÃO, 1999), é fato tácito do ato da compreensão e da formação cognitiva de um contexto (VAN DIJK, 2012). Nesse ínterim, na compreensão, é necessário considerar esse enquadramento e, portanto, essa expectativa para lidar com as "diversas instruções semiológicas" (SALOMÃO, 1999, p. 69).

Isso porque os textos não se apresentam como tais por vontade própria: é necessário reconhecê-los. Saber discernir entre uma piscada acidental e uma tentativa de paquera, entre alguém que acabou de bater a perna e alguém que zomba de um deficiente físico que está passando, se há algo escrito na parede ou se é apenas uma mancha: isso faz parte de nosso cotidiano. A partir dessas decisões fulcrais e a depender delas e da configuração sociocultural envolvida, grandes mal-entendidos podem ocorrer.

Em outros contextos, em contrapartida, o reconhecimento de textos é mais simples, porque, nossas experiências com certas situações ajudam bastante. Há contextos em que esperamos que certos gêneros textuais estejam presentes: por exemplo, podemos esperar em um restaurante (a depender do tipo de restaurante), a presença de um cardápio, dentre outros textos. Em um cinema, um ingresso, um quadro com os horários das sessões, etc. Na rua, não estranhamos a presença de 
um outdoor. Essas expectativas se devem, em parte, ao fato de que podemos lembrar, a partir de nossas experiências anteriores, sobre como as coisas funcionam em diferentes ambientes, e quais gêneros textuais costumam neles "habitar". Existem, enfim, estruturas de expectativa (TANNEN; WALLAT, 2002) não só para situações (por exemplo, quais procedimentos devem ser feitos e quais gêneros textuais provavelmente existem ali) como também para os gêneros presentes nessas situações (que formas, conteúdos e objetivos comunicativos o texto possui). No caso do gênero tira cômica, por exemplo, esperamos, dentre outras prototipicidades, que ele seja engraçado.

Segundo o que Marcuschi (2008) chama de abordagem sociointerativa da cognição, e dentro de uma perspectiva sociocognitiva da linguagem ( $\mathrm{KOCH}, 2011 \mathrm{~b})$, na atividade de compreensão estão envolvidos conhecimentos obtidos a partir das variadas experiências interacionais prévias do indivíduo. Trata-se dos esquemas mentais $(\mathrm{KOCH}, 2011 \mathrm{a})$ : unidades atualizáveis de memória que armazenam conhecimento semântico, procedural e situacional em forma de representações mentais que são seletivamente ativadas na compreensão. Dentre esses modelos de experiência, estão os modelos de contexto (VAN DIJK, 2012), que são construídos e constantemente atualizados pelos usuários da língua em sua interação com o texto. Os modelos de contexto são responsáveis pelo enquadramento (SALOMÃO, 1999) efetuado sobre os sinais textuais e não-textuais tomados como relevantes no evento comunicativo, para que, por exemplo, a compreensão de um texto se processe.

O texto verbal em si é apenas a ponta de um iceberg (HANKS, 2008), já que não só não é o objeto de uma suposta e pura atividade hermenêutica de apreensão de um sentido preexistente pela simples análise da materialidade textual, como também o texto não é o único elemento que serve à compreensão, pois, na verdade, ele se instaura com e se imbrica a outros elementos interacionais e semiológicos relevantes e pode depender de forma essencial desses elementos, para que lhe seja relacionado um sentido (SALOMÃO, 1999). É evidente que, estando nós falando de compreensão textual, o texto é o item focalizado dentro dessa atividade, mas seu sentido não é compreendido apenas através dos elementos propriamente verbais, mas também de, por exemplo, gestos (cf. VEZALI, 2011) e outras pistas de contextualização, como os sinais prosódicos e conversacionais utilizados para indicar, monitorar e inferir sentido (GUMPERZ, 2002). 
Por fim, compreender é construir o sentido de um texto, concretizá-lo (HANKS, 2008), isto é, fazê-lo ser o que ele só é em potencialidade (quando não contextualmente centrado); fazê-lo "mostrar a que veio". A atividade de compreensão é também de preenchimento de espaços vagos de implicitude $(\mathrm{KOCH}, 2011 \mathrm{a})$ e é potencialmente cheia de percalços em seu caminho, justamente porque não é um processo automático de simples decodificação.

A compreensão não tem um limite preciso, isto é, não tem um sentido que seja um alvo específico e único. Marcuschi (2008), nesse sentido, descreve o que chama de horizontes, ou seja, os níveis de alcance da compreensão, que se assemelham com o que Van Dijk (1992) chama de modos de compreender. O horizonte mínimo, assim, corresponde ao nível mínimo de compreensão que abrange minimamente a coerência tanto local quanto global do texto (VAN DIJK, 1992). O horizonte mínimo é aquele que está no nível da leitura parafrástica. Nele, pode-se deixar algo do texto de lado, "selecionar o que dizer e escolher o léxico que nos interessa", mas "nossa interferência é mínima e a leitura fica na atividade de identificação de informações objetivas" (MARCUSCHI, 2008, p. 259).

A compreensão pode incluir outros horizontes (MARCUSCHI, 2008), em que a estratégia de inferência se torna crucial, além de conhecimentos específicos. Além disso, a depender do contexto sociocultural em que transita, o texto pode ser imbuído de sentidos muito pouco inferíveis apenas pelo exame textual per se: é o caso de uma leitura que leve em consideração a ideologia política do autor, de sua contemporânea situação política e as eventuais restrições de liberdade de expressão de alguma configuração política.

De qualquer forma, na análise que fazemos a seguir, nos restringimos apenas ao horizonte mínimo de compreensão, ao abrangermos exclusivamente o alcance cognitivo do sentido de humor da tira cômica, nesse plano parafrástico de que fala Marcuschi (2008). A análise que fazemos não consiste em um exercício hermenêutico pautado em um modelo meramente semiótico da compreensão (SPERBER; WILSON, 1986). Não se trata, tampouco, da simples descrição da produção textual do sentido ou da elaboração textual do humor do texto cômico, seja para somente saber o que causa o humor, seja apenas para saber o papel da língua nele. Trata-se, antes de tudo, da questão do papel do leitor para a construção do sentido e para o efeito de humor: das estratégias cognitivas que o leitor precisa efetuar para construir o humor. 
Quando o leitor percebe o humor do texto, ele não precisa necessariamente refazer o percurso metalinguístico de sua geração, mas construir os sentidos em conflito que geram as famosas "quebras de expectativas". Assim, a compreensão do humor está longe de ser apenas decodificação ou resultado do reconhecimento de um output em que o humor está linguisticamente instalado, mas uma atividade interacional e cognitiva, cujo estudo não deve se constituir em uma sanha de saber se o leitor seria capaz de compreender o humor se se defrontasse com o espécime textual. A compreensão é uma construção, um processo (MARCUSCHI, 2008) e como tal pode demandar diferentes percursos e estratégias (VAN DIJK, 1992). Como lembra Van Dijk (1992, p. 19), “a compreensão não se constitui em uma simples construção passiva de uma representação do objeto verbal, mas parte de um processo interacional no qual o ouvinte ativamente interpreta as ações do locutor".

Assim, nossa análise não consiste em elencar regras para compreender uma tira cômica, mas em levantar algumas estratégias que possivelmente o leitor utilizará no caso do texto coletado. As estratégias não são sempre ótimas, como as regras, e sim "hipóteses operacionais eficazes sobre a estrutura e significado corretos de um fragmento de texto, que podem ser desconfirmadas em processamentos subsequentes": representam "o conhecimento procedural que possuímos sobre compreensão de discurso" (VAN DIJK, 1992, p. 23).

Alguns estudos sobre compreensão (por exemplo, Marcuschi (2007; 2008) geralmente se pautam em dados tipicamente conversacionais em que há pelo menos dois interlocutores presentes em uma situação comunicativa imediata. Às vezes, assumem até a forma de um relato do interlocutor, através de protocolos específicos sobre o que o leitor compreendeu e por que compreendeu daquela forma, como ocorre em alguns estudos em Psicolinguística. Assim, nesse último caso, a compreensão é vislumbrada de forma "meta", praticamente no mesmo momento em que se processa, on line. Na análise feita a seguir, no entanto, nossa contribuição é adotar a análise do texto como profícuo método de entendimento da relação compreensão/texto, ultrapassando, assim, o dualismo entre o estudo da compreensão textual e o da construção textual, denunciado por Flôres e Gabriel (2012). Explicitamos, desse modo, as potenciais estratégias sociocognitivas que envolvem a atividade de compreensão do humor através da análise do construto textual em questão. Para isso, levamos em consideração a maneira como ele é gerado pela leitura do texto. Dito isso, formulamos abaixo a questão que tentamos 
responder, usando a expressão efeito de humor, derivada e especificada a partir da expressão efeito de sentido de Marcuschi (2007). Perguntamos:

- Quais estratégias cognitivas são necessárias para compreender o sentido e o efeito de humor da tira cômica em questão?

\title{
4 CONTEXTUALIZANDO O DADO: A SÉRIE DE TIRAS NÍQUEL NÁUSEA
}

Para que o espécime de tira cômica em questão tenha seu sentido e humor mínimos compreendidos, não será necessário conhecer as informações sobre o cartunista ou sobre os personagens da série da qual faz parte. No entanto, a título de contextualização do dado, apresentamos abaixo algumas informações sobre o cartunista Fernando Gonsales, autor da tira:

\begin{abstract}
Cartunista brasileiro, cujo principal personagem é o rato Níquel Náusea nome que também intitula a tira de jornal em que aparece. Nascido em 3 de fevereiro de 1961, na cidade de São Paulo, formou-se em Veterinária, na turma de 1983 da Faculdade de Medicina Veterinária e Zootecnia da USP e em Biologia, na turma de 1998/1999 do Instituto de Biociências da mesma universidade. Graças a essa formação, muitas vezes insere informações científicas em quadrinhos que retratam de forma divertida características de animais - com personagens que vão de protozoários a dinossauros. Esse tipo de quadrinho, com personagens "soltos", são alternados com as tiras de personagens fixos, entre os quais a barata Fliti, a rata Gatinha o rato Ruter além do próprio Níquel Náusea. Suas tiras foram publicadas inicialmente em 1985, quando ganhou um concurso promovido pelo jornal Folha de São Paulo. Desde então as tiras continuam a ser publicadas neste veículo há mais de 20 anos. Vários outros jornais também passam ou já passaram suas tiras.. ${ }^{2}$
\end{abstract}

Os personagens que aparecem na tira são Níquel Náusea e a barata Fliti. "Níquel é um rato de esgoto cujo nome completo é Níquel Náusea. Como todos sabem, esse nome é inspirado numa personagem de Walt Disney, a vovó Donalda $(\mathrm{sic})$ "3. Sobre Fliti: "As baratas aguentam radiações maciças, altas temperaturas, pressões absurdas. Mas o barato Fliti curte mesmo um bom Baratox de ação prolongaaaaaaaada". 


\section{ANÁLISE DA TIRA}

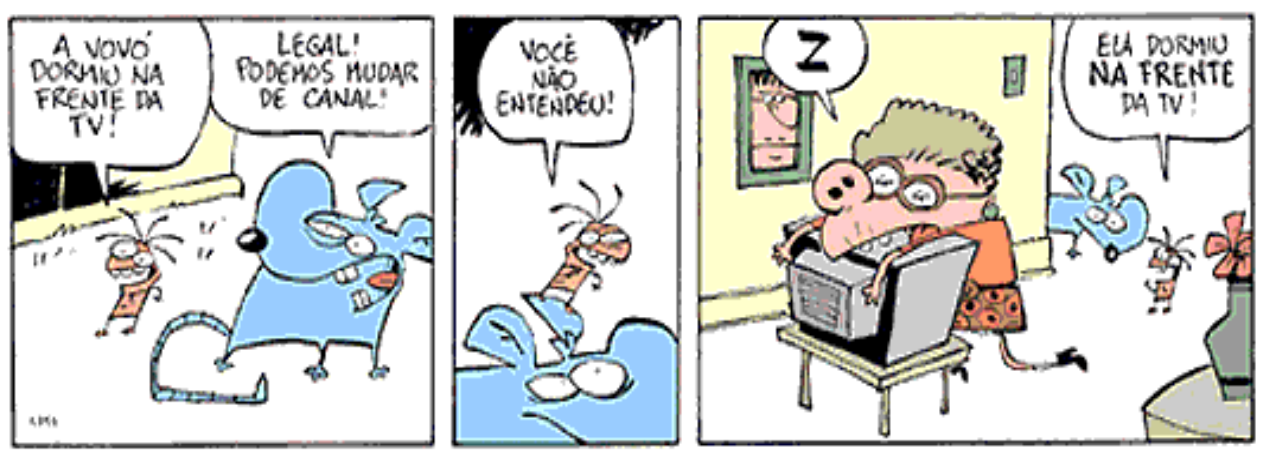

Níquel Náusea, Fernando Gonsales (s/d)

Primeiramente, podemos repetir o que geralmente se diz quando se teoriza sobre piadas: o efeito de humor nessa tira é gerado por uma "quebra de expectativa". Concordamos com essa colocação: ela significa, em termos cognitivos, que o cenário evocado pelo enunciado $A$ vovó dormiu na frente da TV não condiz exatamente com a situação representada pela imagem do terceiro quadrinho, embora o cenário e a imagem tenham relação entre si. No entanto, é evidente que o humor existirá, mesmo que o leitor não especifique metadiscursivamente, como acabo de fazer, onde exatamente está o humor. Além disso, não é apenas essa quebra que provoca o efeito de humor, que é também um efeito cognitivo (com possíveis reverberações somáticas, isto é, riso). O inusitado da situação mostrada no último quadrinho também contribui para esse efeito.

Um conjunto de elementos vai redundar no humor, tais como fatores mais tácitos e secundários, como o estilo estético das formas desenhadas: temos, portanto, a participação do input não-verbal. O que ocorre, assim, é o concurso, redundância ou conjugação (cf. VEZALI, 2010) de elementos não-verbais com elementos verbais, como no enunciado Ela dormiu na frente da $T V$, em que há a ocorrência de negrito. Esse enunciado, particularmente, contém um input visual, devido ao papel de ênfase que o negrito desempenha.

O cenário evocado com o primeiro enunciado é conseguido por uma cristalização semântico-cognitiva presente na língua. Dormir na frente da TV nos remete aos modelos de experiência relacionados ao cotidiano familiar: significa prototipicamente dormir no sofá enquanto se assiste à TV, deixando a TV ligada. Assim, o efeito de humor depende desse formulaico da língua, facilmente reconhecido pela nossa cultura televisiva. A já referida "quebra" se torna mais forte 
se considerarmos que a distância entre essa relação [enunciado/modelo situacional evocado], altamente recorrente na língua, está bem distante da outra relação [enunciado/representação situacional mostrada] que surge no terceiro quadrinho, porque esta não é apenas uma representação de uma situação diferente da primeira, mas de uma situação “inverossímil”, embora não impossível. É fácil notar que esse pressuposto cognitivo em torno da (in)verossimilhança no humor é também necessário, quando se considera a ficcionalidade de qualquer narrativa. $O$ que também parece importante nesta tira, portanto, é o tipo de conhecimento que nos leva a julgar algo como verossímil ou não. É evidente que essa caracterização de uma situação de acordo com seu grau de verossimilhança se pauta em comparações com nossos modelos de experiências com o mundo, e, mais especificamente, com as nossas formas de conhecer o mundo e as propriedades de seus objetos.

O efeito estético de movimentação dos personagens, por sua vez, não contribui de forma direta para a compreensão do sentido, é secundário para sua efetivação, assim como o que acontece com o estilo das formas. Mas esses elementos secundários do texto em questão vão ter outros papéis na atividade de compreensão:

- O balão com um Z, por exemplo, é uma onomatopeia escrita que reitera a informação de que a Vovó está dormindo: é um recurso gráfico ratificador, e está em conjugação com a imagem da Vovó contígua ao enunciado do mesmo quadrinho, indicando que a Vovó dormiu. Além disso, esses elementos não só contribuem para o sentido "menor" de que a Vovó dormiu, mas, juntos, e em relação com o cenário primeiramente evocado, provoca o efeito "maior" do humor ("maior" porque para esse efeito de humor é necessário saber que a Vovó dormiu (input "menor"));

- Os outros enunciados promovem a progressão narrativa, mas também têm papel no jogo de sentidos:

- O enunciado Legal! Vamos poder mudar de canal! ratifica o cenário prototípico evocado de "dormir na frente da TV": na situação mostrada posteriormente na tira, que substitui o cenário evocado, no entanto, mudar de canal não é mais possível;

- O enunciado Você não entendeu gera a expectativa da proximidade do gatilho do humor, como se fosse seguido por reticências ou dois pontos: 
expectativa típica de sequências narrativas que reforça a ideia de mudança de sentido, ajudada também pela própria repetição enfática do enunciado dormiu na frente da TV (afinal, só se repete um enunciado para quem não o entendeu da forma pretendida).

Vimos que o negrito enfatiza o que a imagem da tira mostra, isto é, o lugar onde a Vovó está dormindo. Em si, o negrito destaca esse aspecto da situação, o aspecto lugar do ato de dormir: não é no sofá, é literalmente na frente da TV. O negrito, nesse caso, também tem o papel de guiar a compreensão para um sentido menos cristalizado daquele contido na expressão "estar na frente da TV": a Vovó está tão na frente da TV que a está tapando. Novamente temos a ativação de conhecimentos acerca das convenções linguísticas (e gráficas) cristalizadas.

O fato de o enunciado Legal! Vamos poder mudar de canal ser posto no texto implica que Níquel e Fliti não só gostam de assistir à TV, como também geralmente não conseguem assistir porque a Vovó não Ihes permite fazê-lo. A geração desses conhecimentos por meio do enunciado é uma inferência. No entanto, segundo Marcuschi, essa manobra cognitiva faz parte de outro horizonte de compreensão, que é o horizonte máximo. No caso de nossa tira, essa inferência também não faz parte do efeito de humor propriamente dito, tem papel secundário. No entanto, ousamos teorizar propondo que o sentido de humor pode penetrar esse horizonte máximo, se precisar da ativação de alguma estratégia inferencial, o que colocaria a questão do humor como não sendo uma questão pertencente necessariamente ao horizonte mínimo.

\section{CONCLUSÕES}

A partir de nossos resultados, podemos elencar as seguintes estratégias exigidas para a compreensão do humor da tira analisada:

- A evocação de um cenário correspondente a uma expressão formulaica da língua;

- A evocação de conhecimentos semiológicos diversos em relação aos elementos visuais e verbais do texto, sendo que conhecimentos visuais dependem funcionalmente de conhecimentos verbais e vice-versa; 
- Operações secundárias em relação ao seu grau de importância para a compreensão do humor, como a identificação do estilo cômico das figuras e o reconhecimento do texto como pertencente a um gênero de humor;

- Ativação de conhecimentos mais básicos, que dizem respeito à identificação da verossimilhança, pois se relacionam com o conhecimento do que é ou não plausível.

Notamos que há diferentes graus de importância dessas operações para a compreensão do humor, sendo a identificação da verossimilhança ou plausibilidade a mais básica, seguida da semiologização, isto é, o reconhecimento do caráter textual da tira. Processos mais específicos são: a expectativa de comicidade no texto em questão e, por fim, evocações de cenas situacionais por meio dos elementos verbais e não-verbais. Por fim, podemos dizer que não apenas os sentidos, mas também a mudança de interpretações (inferências?) (as chamadas "quebras de expectativas") no fluxo da compreensão é ratificada pelas diferentes semioses do texto.

Questões mais amplas, que não estão diretamente relacionadas com a pergunta principal deste trabalho, se levantam. Por exemplo, no que a tira cômica se diferencia de outras narrativas, se em muitas a verossimilhança também muda bruscamente? Existem graus diferentes na "narratividade" das tiras e de outros gêneros cômicos? Isto é, existe humor sem narrativa? Por fim: o que há de engraçado na quebra de verossimilhança? Questionar-se sobre o humor é desafiar o racionalismo mais atroz, pois lança luz sobre a história cultural desse espaço de paradoxos (de alegria e de luta ideológica), que é o humor.

\section{NOTAS}

\footnotetext{
${ }^{1}$ Mestrando em Linguística. Instituto de Estudos da Linguagem/ Universidade Estadual de Campinas (IEL/UNICAMP). Licenciado em Letras pela Universidade Federal do Pará (UFPA).

${ }^{2}$ Disponível em: <http://pt.wikipedia.org/wiki/Fernando_Gonsales>. Acesso em: 24 nov. 2012.

${ }^{3}$ Disponível em <http://www2.uol.com.br/niquel/personagens.shtml>. Acesso em: 24 nov. 2012.
} 


\section{REFERÊNCIAS}

BENTES, Anna Christina. Linguística textual. In: MUSSALIM, F.; BENTES, A. C. (Org.). Introdução à linguística: domínios e fronteiras. São Paulo: Cortez, 2007. p. 245-285.

CAGNIN, Antônio Luiz. Os quadrinhos. São Paulo: Ática, 1975.

FLÔRES, O. C.; GABRIEL, R. O quebra-cabeça da leitura: leitor, texto, autor. In: MOURA, H.; GABRIEL, R. (Org.). Cognição na linguagem. Santa Catarina: Insular, 2012. p. 219-236.

GIL, Célia Maria. A linguagem da surpresa. 1991. 220f. Tese (doutorado em Letras Clássicas e Vernáculas)-Faculdade de Filosofia, Letras e Ciências Humanas, Universidade de São Paulo, São Paulo, 1991.

Elementos essenciais da piada. In: ANTUNES, L. Z.; MAIMONE, R. H. (Org.). Estudos de literatura e lingüística. São Paulo: Arte \& Ciência; Assis: UNESP, 1998. p. 295-319.

GONSALES, Fernando. 2 tiras do Níquel. Disponível em: <http://kemvaila.blogspot.com.br/2010/11/2-tiras-do-niquel.html>. Acesso em: 24 nov. 2012.

GRICE, Herbert Paul. Lógica e conversação. In: DASCAL, Marcelo (Org.). Fundamentos metodológicos da lingüística: pragmática. Problemas, críticas, perspectivas da lingüística. Campinas: Unicamp, 1982. p. 51-103.

GUMPERZ, John. Convenções de contextualização. In: GARCEZ, P.; RIBEIRO, B. T. (Org.). Sociolingüística interacional. São Paulo: Loyola, 2002. p. 149-182.

HANKS, William. Língua como prática social: das relações entre língua, cultura e sociedade a partir de Bourdieu e Bakhtin. São Paulo: Cortez, 2008.

$\mathrm{KOCH}$, Ingedore Grunfeld Villaça. Desvendando os segredos do texto. 7. ed. São Paulo: Cortez, 2011a.

. Do cognitivismo ao sociocognitivismo. In: MUSSALIM, F.; BENTES, A. C. (Org.). Introdução à linguística: fundamentos epistemológicos. 5. ed. São Paulo: Cortez, 2011b. p. 251-300.

MARCUSCHI, Luiz Antônio. Cognição, linguagem e práticas interacionais. Rio de Janeiro: Lucerna, 2007.

2008.

. Produção textual, análise de gêneros e compreensão. São Paulo: Parábola,

RAMOS, Paulo. Tiras cômicas e piadas: duas leituras, um efeito de humor. Tese de doutorado. 2007. 177f. Tese (doutorado em Letras Clássicas e Vernáculas)- 
Faculdade de Filosofia, Letras e Ciências Humanas, Universidade de São Paulo, São Paulo, 2007.

RASKIN, Victor. Semantic mechanisms of humour. Dordrecht: D. Reidel, 1985.

SALOMÃO, Maria Margarida Martins. A questão da construção do sentido e a revisão da agenda dos estudos da linguagem. Veredas: Juiz de Fora, v. 3, n. 1, p. 61-79, 1999.

SANTOS, Roberto Elisio. Para reler os quadrinhos Disney: linguagem, evolução e análise de HQs. São Paulo: Paulinas, 2002.

SPERBER, D.; WILSON, D. Relevance: communication and cognition. Cambridge: Harvard University Press, 1986.

TANNEN, D.; WALLAT, C. Enquadres interativos e esquemas de conhecimento em interação: exemplos de um exame/consulta médita. In: GARCEZ, P.; RIBEIRO, B. T. (Org.). Sociolingüística interacional. São Paulo: Loyola, 2002. p. 183-214.

TOMASELLO, Michael. Origens culturais da aquisição do conhecimento humano. São Paulo: Martins Fontes, 2003.

VAN DIJK, Teun Augustus. Cognição, discurso e interação. São Paulo: Contexto, 1992. 2012. . Discurso e contexto: uma abordagem sociocognitiva. São Paulo: Contexto,

VEZALI, Patrik. Linguagem, corpo e afasia. In: MORATO, E. M. (Org.) A semiologia das afasias: perspectivas linguísticas. São Paulo: Cortez, 2010. 